\title{
Pengalaman Ibu Merawat Anak Thalasemia di RSUD Dr.Slamet Garut
}

\author{
Sri Yekti Widadi ${ }^{1}$, Selina Oktaviani ${ }^{2}$
}

\begin{abstract}
Abstrak
Thalasemia adalah kelainan darah yang diturunkan dari orangtuanya, anak dengan thalasemia harus melakukan tranfusi darah secara rutin yang mengakibatkan kelebihan zat besi, selain itu juga harus mengomsumsi obat kelasi besi untuk mengurangi kelebihan zat besi akibat keseringan tranfusi darah yang dilakukan seacra rutin dan jangka waktu lama. Adanya perawatan tranfusi dengan secara rutin. sehingga sangat perlu ibu mendampingi anaknya. Ibu tidak hanya melakukan aktivitas sehari-hari saja melainkan ibu sebagai perawat dimana merawat anak-anaknya yang sakit. sehingga sangat perlu ibu Selama perawatan dan Pengetahuan mengenai thalasemia sangat penting Metode yang digunakan pada penelitian ini adalah kualitatif dengan metode fenomologi dekriptif ini, bertujuan untuk mengeksplor pengalaman ibu merawat anak thalasemia. Hasil penelitian menunjukan 5 tema yaitu 1) Perasaan Ibu pertama mengetahui anaknya Thalasemia (kaget, syok, tidak menerima,menerima), 2) Upaya ibu Mengobati Anak, 3), kendala ibu merawat anak thalasemia, 4) Menerima kenyataan setelah melakukan pengobatan 5) Dukungan yang diperoleh ibu. Kesimpulan Diharapkan tenaga kesehatan termasuk perawat anak dapat memberikan pengetahuan dalam perawatan dan pengetahuan kepada keluarga terutama ibu yang mendampingi anaknya sealama perawatan.
\end{abstract}

Kata Kunci: Thalasemia, perawatan, pengalaman ibu Merawat Anak.

\section{Abstract}

Thalassemia is a blood disorder inherited from parents, children with thalassemia have to do regular blood transfusions that result in excess iron, but also must consume iron chelation drugs to reduce excess iron due to frequent blood transfusion that is carried out routinely and for a long period. The existence of routine transfusion treatment. so it is very necessary for the mother to accompany her child. The mother does not only carry out daily activities, but also as a nurse, caring for her sick children. so it is very necessary for the mother During treatment and Knowledge of thalassemia is very important. The method used in this study is qualitative with this descriptive phenomenology method, aimed at exploring the experience of mothers caring for thalassemia children. The results showed 5 themes that is 1) The feeling of the first mother knowing her child Thalassemia (shocked, shocked, did not accept, accept), 2) Efforts to treat the child's mother, 3), the constraints of the mother caring for thalassemia children, 4) Accepting the reality after treatment 5) Support obtained by the mother. Conclusion It is expected that health workers, including child caregivers, can provide knowledge in care and knowledge to families, especially mothers who accompany their children during care.

Keywords: Thalassemia, care, mother's experience caring for children.

\section{PENDAHULUAN}

Angka kejadian penyakit Thalasemia

di dunia berdasarkan data dari Badan

Organisasi Kesehatan Dunia atau World

Heatlh Organization (WHO) menyatakan, insiden pembawa sifat Thalasemia di Indonesia berkisar 6-10\%, artinya dari setiap 100 orang 6-10 orang adalah pembawa sifat Thalasemia, Berdasarkan 
data dari Yayasan Thalasemia Indonesia, kasus thalasemia (kelainan sel darah merah) mayor di Indonesia terus meningkat sejak lima tahun terakhir. Pada tahun 2012 terdapat 4.896 kasus thalasemia mayor dan pada 2017 terus meningkat menjadi 8.616 kasus (Kemenkes, 2018)

Di Provinsi Jawa Barat sendiri jumlah penderita Thalasemia memiliki jumlah penderita terbanyak di Indonesia menunjukkan angka yang tinggi dengan pencapaian angka 3.264 penyandang Thalasemia di akhir tahun 2017 . Berdasarkan data yang di peroleh Yayasan Thalasemia Indonesia (YTI) dan Perhimpunan Orang Tua Penderita Thalasemia Indonesia (POPTI) mei 2018, Jumlah ini menunjukkan $40,2 \%$ dari total kasus Thalasemia nasional dan menempatkan provinsi Jawa Barat pada peringkat tertinggi untuk jumlah penyandang talasemia di Indonesia. Berdasarkan data yang diperoleh mei 2018 Pencegahan dan Pengendalian Penyakit (P2P) Dinas Kesehatan Kabupaten Garut tercatat lebih dari 270 warga menderita Thalasemia mayor sehingga harus selalu melakukan tranfusi darah (Dinkes,2018). Data yang diperoleh di rekam medik RSUD dr.Slamet Garut didapatkan angka penderita Thalasemia pada bulan januari sampai november 2018 mencapai 226.

Thalasemia merupakan Penyakit kelainan darah yang menyebabkan sel darah (hemoglobin) merah cepat hancur sehingga usia sel-sel darah menjadi lebih pendek umurnya dari sel darah normal pada umumnya bertahan hingga 120 hari, ditandai dengan anemia (Sukri, 2016). Berdasarkan tingkat keparahannya, Thalasemia dibagi menjadi tiga jenis Thalasemia yaitu minor, intermedia, dan mayor. Pada penderita Thalasemia minor dan intermedia yang bersifat ringan sehingga tidak membutuhkan tranfusi darah yang rutin (Wong, 2009).

Anak dengan Thalasemia mayor harus melakukan tranfusi darah secara rutin dan teratur. Namun pada tranfusi darah dapat memberikan efek samping, dimana kelebihan zat besi yang menyebabkan kerusakan liver, jantung, dan organ lainnya, (Kiswari, 2016). Sehingga anak harus mengkomsusi obat kelasi besi untuk menguarangi kelebihan zat besi akibat keseringan tranfusi darah yang dilakukan secara rutin dalam jangka waktu yang lama. Hal inilah peran keluarga terutama ibu dan peran perawat penting untuk anak thalasemia.

Studi pendahuluan yang dilakukan diruang poli thalasemia RSUD dr.Slamet Garut pada tanggal 7 Desember 2018 didapatkan data dari bulan november 2018 terdapat 226 penderita thalasemia yang sedang dalam pengobatan diruang poli thalasemia RSUD dr.Slamet Garut. Berdasarkan hasil wawancara dengan tiga orang ibu yang mempunyai anak thalasemia dan sedang 
menjalani anak menjalani tranfusi darah di RSUD dr.Slamet garut. Ibu yang pertama mengatakan sedih saat mengetahui anaknya dikatakan thalasemia, dan mengeluh saat ketidak sediaan darah pada saat melakukan terapi tranfusi sehingga ibu harus ke pelayanan kesehatan lain. Ibu yang kedua mengatakan tidak menerima pertama kali mendengar anaknya thalasemia karena merasa sebaik-baik mungkin dalam merawat anaknya, Ibu yang ketiga mengatakan kaget saat mendengar anaknya thalasemia, adanya kekhawatiran masa depan pada anak akibat sering meninggalkan sekolah, melantarkan anak yang lain, meninggalkan pekerjaannya.

\section{METODE PENELITIAN}

Metode penelitian ini menggunakan metode kualitatif dengan pendekatan fenomenologi. Pengambilan sampel yang digunakan yaitu purposive sampling dengan jumlah tiga orang informan dan teknik pengumpulan data berupa wawancara mendalam.

\section{Adapun}

langkah-langkah menganalisa data menurut Colaizzi dalam Streubert dan Carpenter, 2003. Mendengarkan hasil wawancara dengan informan, membaca hasil transkip yang sesuai dengan pernyataan partisipan, menguraikan arti kandungan sesuai dengan peryataan partisipan untuk di jadikan kata kunci, melakukan pengkatagirian kata kunci dalam sub-sub tema yang baru, mendeskripsikan tema tema yang sudah ada secara lengkap berdasarkan pengalaman ibu dengan anak thalasemia. Melakukan pertemuan kembali dengan pengalaman ibu dengan anak thalasemia yang telah di jadikan informan untuk melakukan uji keabsahan., merevisi isi pernyataan sesuai dengan hasil uji keabsahan.

\section{HASIL DAN PEMBAHASAN}

\section{Hasil Penelitian}

Informan dalam penelitian ini terdapat 5 perempuan dengan usia mulai dari 27-45 Tahun, dengan tingkat pendidikan terakhir mulai SD dan SMA/SMK, dengan pekerjaan yaitu ibu rumah.

Penelitian ini mengungkapkan 5 tema :yaitu: 1) Perasaan Ibu pertama mengetahui anaknya Thalasemia, 2) Upaya ibu Mengobati Anak, 3) kendala ibu merawat anak thalasemia, 4) Menerima kenyataan setelah melakukan pengobatan 5) Dukungan yang diperoleh ibu.

\section{a. Perasaan Ibu pertama mengetahui anaknya Thalasemia.}

ketiga partisipan mengalami tahap kaget, syock, dan tidak menerima kenyataan masa duka pada saat pertama kali mengetahui anaknya mengenai Thalasemia.

"Raraosan mah kumahanya (Ibu tampak bingung), da kermah teterangnya panyawat ieu teh naon, asa rewas weh 
neng pertama ngadangu mah bari kedah d tranfusi teras... (P1)”

"Ah ngedrop neng (mengerutkan kening) ,teu sadar neng dugi ka sabaraha hari, pas terang si ade kieu teh, naha bet tiasa kieu, naha awalna kumaha, ngawitan mah ah terguncng weh neng... (P4)"

" soak neng... ,tidinya teh ibu teh teu ngiringan $K B$, ayeunamah ngiringan $K B$ da soak neng, perasaan ibu teh da tos bener ngarawat si ade teh (sambil mengerutkan kening), upami enjing-enjing sok $d$ poyankeun ,tapi naha bet tiasa kieu.... (P5)".

Namun ada dua partisipan yang dapat menerima kondisi anaknya. Respon positif muncul pada ibu yang memilki kedua anaknya sabar dan pasrah, ada juga pada partisipan ini dengan cepat bisa berada dalam fase penerimaan karena kesabaran dan berserah diri kepada Alloh SWT.

"ahh terima weh neng tos kedahna, jadi teu kaget teuing soalna kaka na sebelumna Thalasemia jadi gak kaget.. "(P2)

"kitu tea weh neng da tos kumaha etamah ujian ti alloh neng, da sanes kahoyong,sadayana panyakit ge da aya landongna... (P3)".

\section{b. Upaya ibu mengobati penyakit anak}

informan menyatakan bahwa perawatan yang dilakukan ibu mengenai anaknya yaitu diantaranya :

1. mengatur pola makanan

" perawatana mah eta weh neng tina tuangeun teu kengeng nu zat besi saur perawatna nateh neng ..(Pl)”

"Makanan kedah dijagi neng...(P3)"

"Dijagi pola makana neng (P4)

2.Ibu mengatur aktivitas anak

"paling teu kengeng kacapean ulah siga nu sanes, upami aya kagiatan disakola dipiwarang teu kengeng ngiringan, mun wih sakola ge atos calik dibumi da kacapean mah bilih ngedrop...(P2)"

"teu kengeng kacapean oge neng...(P3)"

"aktivitas na dikirangan ,komo saageung kieu mah neng ah nuju mejeuh-meujeuhna (tertawa-tawa) awalnamah teu terang upami aktivitas aktif pisan otomatis sidarahna teh enggal lungsurna, konsul konsul ka dokter ayeunamh dijagi weh ,Kadang sharing sareng ibu-ibu sami nu putra na Thalasemia...(P4)

melakukan tranfusi ,dan mencari informasi sharing dengan tenaga kesehatan atau dengan ibu-ibu yang sama.

"Dipiwarang tong seer ameng-amengan, da ade mah benten sareng nu sanes sok dikitukeun neng ku ibu mah, upami disakola ge pan sok aya olahraga tara ngiringan ,kadang tara masuk sakola upami aya jadwal olahraga mh neng (ibu sambil senyum-senyum)...(P5)".

3. Partisipan juga berusaha dalam mencari informasi tentang penyakit anaknya "pas pertama kan teu terang aktivitas kedah dibatasi, jadi konsul ka dokter atau sharing sareng ibu-ibu nu sok aya didieu sami nu ngantosan tranfusi putra na neng (sambil senyum) ...(p4)”

\section{c. Kendala ibu dalam merawat anak thalasemia}

lima informan didapatkan beberapa pernyataan, informan menyatakan bahwa kendala perawatan ibu mengenai anaknya yaitu diantaranya :

1. keterbatasan aktivitas

"paling neng upami beberes dikintun hela da tranfusi (P1)"

"Kadang sok dikintun hela neng beberes dibumi, kadang sok gantian sareng suami soalna kan ibu mah anak dua-dua na tranfusi (P2)” 
"kadang neng beberes dikantunkeun hela (P3)"

"paling eta neng upami beberes dikantun hela da ade kedah tranfusi RS..(P4)”

2. kesulitan ekonomi

"Eta neng upami teu aya artos kanggo ongkos.. (P3)"

kadang sok stress neng kahiji artos kanggo ongkos, si ade tos pucet, upami tos bade tranfusi teh, sakedap dei si ade tranfusi kedah aya acis kanggo ongkos kadang ibu mah sok kitu neng, komo neng pas pertama ngangge umum da teu acn ngadamel bpjs ah neng artos teh lumayan, tapi alhmdulilah ayeunamh tos ngangge bpjs ... (P5)"

\section{d. Menerima kenyataan setelah}

melakukan pengobatan

Informan menyatakan merima anaknya setelah lama melakukan perawatan anakanya adalah sabar, menerima kenyataan, berusaha menerima, dan memasrahkan diri.

"Ah neng kedah sabar, da sanes kahoyong neng, da kahoyong mah damang, tapi ari tos kedahna dipasihan kieu mah nya terima weh neng (P1)"

"..ah berusaha menerima weh neng ari tos kedah kumaha dei..(p2)”

"..dijalani weh neng tos kedahna kieu ,sabar neng...(P3)"

"sabar neng terima weh ,tos kedahna kieu ti alloh.. (P4)"

"ah nerima neng ayeunamah, wios keun neng pasrahkeun weh ka alloh neng ibu ma..(P5)

\section{e. Dukungan yang diperoleh ibu dalam} merawat anak thalasemia.

Lima informan didapatkan beberapa pernyataan, informan menyatakan merima anaknya setelah lama melakukan perawatan anakanya adalah sabar, menerima kenyataan, berusaha menerima, dan memasrahkan diri.

"Tikeluargi neng kedah lebih diperhartoskeun.. (P1)",

" ti suami neng alhmdulilah bagi-bagi tugas neng, ibu mah utri duanana thalasemia, jadi baak nu nyandak hela ka RS. Ibu dibumi beberes hela, atos beres nyusul ka RS kitu neng (P2)"

"Alhmdulilah neng kedah sabarr.. pas awal awal pan sesah nya alit keneh mah alim nangis, sok dianter ku keluarga upami tranfusi teh cukup lumayan lami...(P3),"

" alhmdulilah neng sok kadang aya nu kers donor darah ti keluargi, teras sok ngajajap ka $R S$,

"ti keluarga alhmdulilah upami teu gaduh acis sok dipasihan nambut neng, ti keluarga alhmdulilah upami teu gaduh acis sok dipasihan nambut neng. (P5)"

\section{Pembahasan}

Ibu yang memiliki anak dengan thalassemia mengalami gangguan psikologis, seperti merasa tidak menerima kenyataan, kesedihan dan rasa bersalah Prasomsuk et al., 2007; Commodari, (2010) dalam Yadi Afrida, dkk. (2016). Masa awal saat anak didiagnosis dengan penyakit kronik, ibu mengalami gejolak emosi dan ciri khas pada keadaan ini adalah syok, tidak percaya dan menolak Hockenberry \& Wilson, (2009) dalam Fetriyah Hanik U, dkk (2016).

Pada partisipan pada saat pertama kali mendengar anaknya thalasemia syock, sedih dan tidak dapat menerima kenyataan. Penelitian ini didukung dengan didukung oleh penelitian Fetriyah Hanik Umi, dkk, menyatakan bahwa terdapat ibu yang 
pertama kali mengetahui anak nya mengenai Thalasemia, Tidak menerima kenyataan (ibu mengalami perasaan kaget, sakit hati dan bingung saat pertama kali mengetahui anak mengalami thalassemia).

Anak dengan thalasemia akan membutuhkan dan harus menjalani tranfusi darah yang teratur untuk mempertahankan kehidupannya, selain itu anak juga harus mengkonsumsi obat kelasi besi yang bertujuan untuk mengurangi kelebihan zat besi akibat transfusi darah yang dilakukan secara rutin dan dalam jangka waktu lama Hockenberry \& Wilson (2009) dalam Renylda Reta (2018).

Hasil yang didukung dalam penelitian Hasil penelitian Isworo Atyanty, dkk (2012) menunjukkan bahwa dengan mengomsumsi kandungan zat besi yang tinggi yang terdapat pada penelitian ini bahwa banyak responden yang mengandung zat besi, sehingga rata-rata kadar hemoglobin 7,99 sebanyak 59, 49\% dengan mengomsumsi makanan dengan tinggi zat besi, sehingga harus diperhatikan dalam makanan pada anak thalasemia.

Thalasemia mayor akan mengalami gangguan sintesis rantai beta sehingga akan terbentuk sel darah merah yang kandungan Hbnya kurang. Selain itu rendahnya jumlah sel darah merah atau tidak cukupnya hemoglobin pada sel darah merah, sehingga menyeababkan sel darah merah gagal terbentuk dengan baik dan tidak dapat membawa oksigen yang cukup, dan terjadilah anemia (sukri 2016).

Hal ini didukung oleh penelitian Sumiarsih dwi (2016) menunjukan bahwa respon fisik pada thalasemia mayor seluruh partisipan dengan aktivitas sehari-harinya biasa seperti anak- anak pada umunya, namun keluarga selalu memantau dan membatasi kegiatan bermainnya, mengingatkan kondisinya yang tidak maksimal untuk beraktivitas sehari-hari.

Ibu akan selalu berusaha mengupayakan dan melakukan hal-hal yang terbaik untuk kesembuhan anaknya. Menurut Wong, 2009 mengungkapkan mekanisme koping yang dapat digunakan. menanyakan informasi berkenaan dengan diagnosa dan kondisi anak pada saat ini . Mencari pertolongan dan dukungan orang lain ( dari dalam maupun luar).

Hasil penelitian seseorang yang memiliki pengetahuan yang luas akan cenderung berperilaku hidup sehat dan sadar tentang pentingnya pemeliharaan kesehatan serta kesejahteraan keluarga. membawa optimisme pada orangtua dan memberikan kekuatan untuk melakukan perawatan rutin pada anak yang otomatis akan meningkatkan kualitas hidup.

Keluarga harus menyediakan waktu lebih banyak untuk menemani anak menjalani pengobatan dan begitu finansial untuk biaya pengobatan anak. Sehingga keluarga juga sangat cemas terhadap anaknya sehingga keluarga sangat 
overprotektif pada anak (Wong et al, 2009). Penelitian yang dilakukan indriani (2011) dimana bahwa ibu menyatakan biaya untuk tranfusi, obat kalesi dan pemeriksaan rutin pda thalasemia ,selain itu tranportasi biaya ke rumah sakit dan biaya hidup selama dirumah sakit, biaya untuk sehingga ketidakmampuannya untuk membiayai perawatan Thalasemia.

Suatu untuk memecahkan masalah atau menguarngi stress yang diakibatkan atau peristiwa dengan strategi koping keluarga eksternal ,menurut friedman, dkk, (2010) yaitu : 1) mencari informasi, keluarga yang mengalamai kecemasan memberikan respon secra kognitif dengan cara mencari pengetahuan dan informasi yang berhubungan dengan stressor. 2) Memelihara hubungan afektif dengan komunitas, merupakan suatu koping keluarga yang berkesinambungan, dimana anggota keluarga adalah partisipanpartisipan dalam organisasi, misalnya pada kasus thalasemia, terdapat yayasan thalasemia indonesia, 3) mencari sistem pendukung sosial,merupakan strategi koping keluarga eksternal yang utama, 4) mencari dukungan spiritual, kepercayaan kepada tuhan dan berdoa didefinisikan oleh keluarga sebagai cara paling penting bgi keluarga dalam mengatasi suatu stressor yang berkaitan dengan kesehatan. Hasil Penelitian ini didukung oleh Yati Afrida, dkk (2016). Menunjukan bahwa thalasemia merupakan cobaan/ujian dari

Allah.Penyikapan terhadap anaknya yang menderita talasemia didasarkan secara positif dan negatif.

Ada juga yang didukung oleh penelitian Hamsya (2015)menyatakan bahwa sikap pasrah juga dapat memberikan peranan pada ibu dalam menjalani rutinitas kehidupan bersama anak thalassemia, menjadi lebih terlibat pada apa saja yang dilakukannya, serta yakin dapat membuat suatu perubahan ke arah lebih baik.

Orangtua terutama ibu selama merawat anak Thalasemia, ibu akan mengalami suka duka dan hal tersendiri bagi pengalaman ibu. Pada saat ibu menerima dukungan dukungan dari Suami, Keluarga besar, teman/tetangga, sesama ibu yang merawat anak thalassemia dan tenaga kesehatan. Seperti smangat, motivasi, mendengarkan keluh kesah dan materi akan sangat berguna untuk ibu, terdapat menurut sherbune dan stewart bentuk dukungan sosial (1) dukungan emosianal merupakan dukungn yang berhubungan dengan emosional (2) dukungan instrumental merupakan dukungan dalam bentuk bantuan nyata (3) dukungan pemberian informasi merupakan dukungan bentuk informasi yang tepat dan akurat (4) Dukungan penilaian berupa nasehat dan saran dari orang-orang terdekat (5) menemani reaksi merupakan menemani aktifitas reaksi dapat 
memberikan efek tenang pada diri seseorang.

Penelitian Pratiwi Dian K, menyatakan bahwa dukungan sosial yang ibu diperankan adalah dukungan emosional, intrumental, pemberian informasi, penilaian dan reaksi sedangkan peran ayah memberikan bentuk instrumental dalam bentuk materi, hal inilah yang mempengaruhi oleh faktor umur penderita, pengetahuan orang tua $\mathrm{dn}$ kondisi sosial, ekonomi dan budaya.

\section{KESIMPULAN DAN SARAN}

Hasil wawancara pada ibu "Pengalaman ibu merawat anak Thalasemia di RSUD Dr.Slamet Garut Tahun 2019". Tema yang teridentifikasi dari hasil wawancara adalah sebanyak Enam tema yang memaparkan sebagai pengalaman ibu merawat anak Thalasemia Di RSUD Dr.Slamet Garut. Tema tersebut adalah : 1) Perasaan Ibu pertama mengetahui anaknya Thalasemia, 2) Upaya ibu Mengobati Anak, 3) kendala ibu merawat anak thalasemia, 4) Menerima kenyataan setelah melakukan pengobatan 5) Dukungan yang diperoleh ibu.

1, 2 STIKes Karsa Husada Garut Email: sriyekti_s@yahoo.com

\section{DAFTAR PUSTAKA}

Bakrie mariam. 2017. Asuhan keperawatan kelurga. Jogyakarta : Pustka mahardika
Babara jane dkk 2011, Fundamental Keperawatan Konsep, Proses, \& Praktik, Jakarta, P.O Box 4276.

Betan, 2013. Asuhan Keperawatan Keluarga Konsep dan Praktik. Yogyakarta : Nuha Medika

Data Rekam Medik RSUD dr.Slamet Garut 2018 Angka anak Thalasemia

Fetriyah hanik Umi dkk. 2016. Pengalaman ibu merawat anak usia sekolah dengan beta thalasemia mayor Di RSUD Ulin Banjarmasin. Jurnal Dinamika Kesehatan, Vol 7, November 2016.

Friedman., Marlyin, M., Bowden, V.R., \& Jones, E.G. (2010). Buku Ajar Keperawatan Keluarga, Riset, Teori \& Praktik. Edisi 5. Jakarta : Buku Kedokteran EGC.

Hamsyah, Meiyla \& sakti, Hastaning Hardinness Ibu yang memilki anak dengan Thalasemia, Jurnal Empati Oktober 2015, Volume 4 ,Hal 217224. Fakultas psikologis, Universitas Dipenogoro.

Indriani G 2011. Pengalaman Ibu Dalam Merawat Anak dengan Thalasemia. Program Studi Magister Ilmu Keperawatan Fakultas Ilmu Keperawatan, Universitas Indonesia. Jakarta.

Isworo Atyanty, dkk. Kadar Hempglobin, Status Gizi, Pola Konsumsi Makanan, dan Kualitas Hidup Pasien Thalasemia, Jurnal Keperawatan Soedirman (The soedirman journal of nursing). November 2012, Volume 7, Universitas Jenderal Soedirman.

Maryunani Anik 2010, Ilmu Kesehatan Anak Dalam Kebidanan, Jakarta, CV Trans Info Media.

Moleong, Moleong, Lexy J. 2011. Metodologi Penelitian Kualitatif. Bandung : Remaja Rosdakarya.

Maria Avanty dkk. 2014. Pengalaman Ibu dalam merawat anak likeumia. Jurnal Online Mahasiswa. Program study ilmu kesehatan. Vol 1 No 1.

Nurlaila, Utami,Cahyani. 2018. Buku Ajar Keperawatan Keluarga Anak. Jogyakarta : Leutikaprio. 
Nursalam 2013, Manajemen Keperawatan, Jakarta, Selemba medika.

Salsabila Dara \& Fithria 2017. Beban Keluarga Dalam Merawat Anak yang Menderita Thalasemia. Jurnal Ilmiah Mahasiswa Fakultas Keperawatan. Vol 2, No 3.

Sukri Ahmad 2016, Mengenal, Mendamping \& merawat Thalasemia. jakarta : bee media pustaka.

Sembiring Karta PS. 2010. Thalasemia. Medan : Morphostlab E-Bookpress.

Sugiono (2017). Metode Penelitian kualitatif \& kuantitatif. Bandung : Alfabeta.

Susilaningrum, Rekawati \& dkk. 2013. Asuhan Keperawatan Bayi dan Anak. Jakarta : Salemba Medika.

Ray Lusiana R, dkk. Hubungan Pengetahuan dan Sikap Orangtua dengan Kualitas Hidup Anak Penderita Thalasemia. Seminar Nsional Keperawatan "Tren Perawatan Paliatif sebagai Peluang Praktik Keperawatan mandiri”. Program Studi Keperawatan Fakultas Kedokteran Universitas Sriwijaya.
Pratiwi Dian K 2017. Dukungan Sosial Orang Tua Dalam Pengobatan dan Perawatan pada Anak Penderita Thalasemia (Studi Kualitatif di RSUD Dr. Soetomo Surabaya). Skripsi thesis, Universitas Universitas Airlangga.

Wong, Donna L., Hockenberry, M., Wilson, D., Wilkelstein, M.L., Schawartz, P., 2009. Buku Ajar Keperawatan Pediatrik wong (edisi 6 vol 1). Jakarta: Penerbit Buku Kedokteran EGC.

Wong, Donna L., Hockenberry, M., Wilson, D., Wilkelstein, M.L., Schawartz, P., 2009. Buku Ajar Keperawatan Pediatrik wong (edisi 6 vol 2). Jakarta: Penerbit Buku Kedokteran EGC.

Yosep Iyus. 2011. Keperawatan Jiwa. (Edisi Revisi). Bandung : Penerbit PT Refika Aditama.

Yati Afridk, dkk. Pemaknaan Ibu Merawat Anak Thalasemia di Kota Bandung. (The Meaning Of The Mothers Who Children in). Jl. Telekomunikasi No. 01, Terusan Buah Batu, Bandung, Jawa Barat 40257 Vol. 3, No.2 Agustus 2016. 